ARTICLE

Received 18 Aug 2014 | Accepted 3 Nov 2014 | Published 11 Dec 2014

DOI: $10.1038 /$ ncomms 6732

OPEN

\title{
TRPA1 is essential for the vascular response to environmental cold exposure
}

\author{
Aisah A. Aubdool', Rabea Graepel ${ }^{1}$, Xenia Kodji ${ }^{1}, K^{1}$ hadija M. Alawi', Jennifer V. Bodkin ${ }^{1}$, Salil Srivastava ${ }^{1}$ \\ Clive Gentry ${ }^{2}$, Richard Heads ${ }^{1}$, Andrew D. Grant ${ }^{2}$, Elizabeth S. Fernandes', Stuart Bevan ${ }^{2}$ \& Susan D. Brain ${ }^{1}$
}

The cold-induced vascular response, consisting of vasoconstriction followed by vasodilatation, is critical for protecting the cutaneous tissues against cold injury. Whilst this physiological reflex response is historic knowledge, the mechanisms involved are unclear. Here by using a murine model of local environmental cold exposure, we show that TRPA1 acts as a primary vascular cold sensor, as determined through TRPA1 pharmacological antagonism or gene deletion. The initial cold-induced vasoconstriction is mediated via TRPA1-dependent superoxide production that stimulates $\alpha_{2 C}$-adrenoceptors and Rho-kinase-mediated MLC phosphorylation, downstream of TRPA1 activation. The subsequent restorative blood flow component is also dependent on TRPA1 activation being mediated by sensory nerve-derived dilator neuropeptides CGRP and substance P, and also nNOS-derived NO. The results allow a new understanding of the importance of TRPA1 in cold exposure and provide impetus for further research into developing therapeutic agents aimed at the local protection of the skin in disease and adverse climates.

\footnotetext{
${ }^{1}$ BHF Cardiovascular Centre of Excellence and Centre of Integrative Biomedicine, Cardiovascular Division, King's College London, London SE1 9NH, UK. ${ }^{2}$ Wolfson Centre for Age Related Diseases, King's College London, London SE1 1UL, UK. Correspondence and requests for materials should be addressed to S.D.B. (email: sue.brain@kcl.ac.uk).
} 
$\mathrm{M}$ echanisms involved in the vascular response to cold have been under study for decades. ${ }^{1}$. Local cold exposure in mammals leads to an initial, rapid-onset vasoconstriction that protects against heat loss and this is followed by recovery, involving vasodilation, which is essential to protect the area against local cold-induced injuries, such as chilblains and susceptibility to frostbite ${ }^{1-3}$. Mammals respond to cool temperatures with vasodilatation, which is associated with rewarming and a healthy peripheral vasculature ${ }^{3}$. A loss of coldinduced reflex recovery, associated with vasodilatation is a marker of peripheral vascular disease or injury, leading to painful conditions such as Raynaud's disease ${ }^{4}$. Despite heavy debate, the mechanisms behind the mammalian cold-induced reflex remain unclear and the cutaneous thermosensitive components are unknown. Studies have focused on sympathetic constrictor mechanisms as a primary driver, with some evidence of sensory nerve involvement ${ }^{5}$.

We hypothesized that the cold $\left(<17^{\circ} \mathrm{C}\right)$ sensitive and nonselective cation channel, transient receptor potential ankyrin-1 (TRPA1) channel ${ }^{6}$, may play a pivotal physiological role in coldinduced vascular responses. The role of TRPA1 as a thermosensor in vascular responses is unexplored, although it has been shown to act as a cold sensor in Chinese Hamster Ovary cells in $\mathrm{Ca}^{2+}$ imaging studies ${ }^{6}$ and be involved in mediating cold-induced hyperalgesia in pathological states ${ }^{7-10}$. TRPA1 activation by a range of exogenous and endogenous mediators can occur by covalent activation of the cysteine residues localized to the amino terminus ${ }^{11}$. There is little information on the endogenous role of TRPA1 in cardiovascular regulation at present. Previous studies have shown that TRPA1 agonists, either the exogenous vegetablederived agonist mustard-oil or the endogenous agonist 4-oxononenal (4-ONE), mediates cutaneous vasodilatation via the activation of sensory nerves, but the physiological relevance of this is unknown ${ }^{12-14}$. However, TRPA1-mediated constrictor responses have not been observed. TRPA1 agonists mediate dilation of peripheral resistance arteries in vitro, especially in vessels, such as the cerebral vasculature ${ }^{15,16}$.

The goal of this study is to determine whether TRPA1 plays a role as a vascular sensor of noxious cold, either initiating responses or acting downstream of other cold-sensing proteins. The experiments were designed using a novel murine in vivo model of local acute environmental cold exposure in skin. To achieve this, cutaneous blood flow was measured with a full-field laser perfusion imager (FLPI) in vivo in genetically modified mice and pharmacologically designed experiments. Ex vivo molecular and biochemical techniques were used to delineate the role of TRPA1.

\section{Results}

Local cold-induced vascular response is dependent on TRPA1. The cold model was developed and characterized in male anaesthetized wild-type (WT) mice (8-12 weeks). Following baseline blood flow measurements, the ipsilateral hindpaw was immersed in cold water $\left(10^{\circ} \mathrm{C}\right.$ for $\left.5 \mathrm{~min}\right)$, whilst the contralateral paw remained untreated at room temperature. Exposure to temperatures from 4 to $23{ }^{\circ} \mathrm{C}$ (Supplementary Table 1) revealed that the vasoconstriction response to $10^{\circ} \mathrm{C}$ exhibited substantial TRPA1 dependency. Blood flow was then assessed immediately following cooling, for $30 \mathrm{~min}$ using FLPI, to allow dynamic measurement, at a time period chosen to ensure the response to cold exposure was complete (Fig. 1a). The maximum vasoconstriction was observed at 0 to 2 min following local cooling and determined as the $\%$ maximum decrease in blood flow from the precooling baseline (Fig. 1a-c and Supplementary Fig. 1). This response was substantially less in TRPA1 knockout (KO) mice and in WT mice pretreated with the TRPA1 antagonist HC030031 (ref. 17) (Fig. 1c). It was not technically feasible to measure blood flow with the FLPI during cold $\left(10^{\circ} \mathrm{C}\right)$ water immersion. However, an increased clearance, indicative of active constriction, was measured by ${ }^{99 \mathrm{~m}}$ Technetium clearance during cooling and this response was not observed in the presence of the TRPA1 antagonist (Supplementary Fig. 2). WT and TRPA1 KO mice have similar cardiovascular parameters at baseline (Supplementary Fig. 3) and there was no significant change in vascular responses to immersion in $26^{\circ} \mathrm{C}$ water (Supplementary Table 1). Thus, TRPA1 mediates the initial vasoconstrictor response of the local cold-induced vascular response. The restorative response involves vascular relaxation, which follows the constrictor phase and is measured as area under the curve (AUC) (Fig. 1a,d and Supplementary Fig. 1). This response involves blood flow recovery to baseline levels, referred to as the 'restorative phase' of the cold-induced vascular response.

There is debate and conflicting evidence concerning the relative importance of TRPA1 as a primary cold sensor in cells and in vivo models. TRPM8 (sensitive at temperatures $<25^{\circ} \mathrm{C}$ (ref. 17)) rather than TRPA1 is considered to have a major role in the response to deep body cooling ${ }^{18}$ and in cold-induced pain behaviours ${ }^{19}$. Here the cold-induced vasoconstriction was partially but significantly reduced in TRPM8 KO mice or in WT mice pretreated with the TRPM8 antagonist AMTB compared with control groups (Fig. 1e,f). AMTB pretreatment did not further modify the cold-induced vascular response in TRPA1 KO mice (Fig. 1h) and hence these results indicate that TRPM8 is involved, but played a secondary role to TRPA1 in the cold-induced vascular response in this study. Whilst the TRPA1 antagonist HC030031 abolished vasodilation induced by the exogenous TRPA1 agonist cinnamaldehyde in the mouse ear, AMTB had no effect (Supplementary Fig. 4A-C), suggesting that the pharmacological blockade of TRPM8 does not influence the vascular effects of TRPA1 to other agonists. The results for the restorative increased blood flow response following local cold exposure (Fig. 1f,g,i) show a return to baseline levels in each case, the magnitude of which correlates with that of the vasoconstrictor response. TRPA1 is co-expressed in $60-75 \%$ of TRPV1-expressing sensory C-fibre nerves ${ }^{6,20}$. However, neither pretreatment with the TRPV1 antagonists SB366791, AMG9810 nor gene deletion of TRPV1 altered cold-induced vascular responses (Supplementary Table 2). Mice with TRPV4 gene deletion (a predicted warm temperature sensor of $25-34^{\circ} \mathrm{C}$ ) (refs 21,22 ) were similarly not affected (Supplementary Table 2).

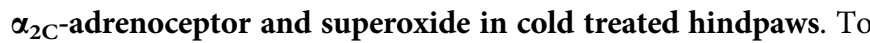
investigate whether TRPA1 could stimulate the initial vasoconstrictor phase via noradrenaline release from sympathetic nerves, noradrenaline concentration was measured in cold-treated and untreated-hindpaw tissue samples collected at the peak of the cold-induced vasoconstriction. Tissue noradrenaline concentration was significantly decreased in the WT cold-treated hindpaw, as assessed by enzyme linked immuno sorbent assay (ELISA). This is possibly as a consequence of the intense vasoconstriction and short half-life of noradrenaline. The noradrenaline concentrations were unchanged in the cold-treated hindpaw of TRPA1 KO (Supplementary Fig. 5).

Furthermore, guanethidine-induced depletion of the peripheral sympathetic nervous system or the pretreatment with the $\alpha$ adrenoceptor antagonist phentolamine caused a partial but significant effect on the cold-induced vasoconstriction (Fig. 2a,b). However, $\alpha_{2 \mathrm{C}}$-adrenoceptors have been shown to influence cold-induced vascular responses ${ }^{23,24}$, and pretreatment with the non-selective $\alpha_{2}$-adrenoceptor antagonist yohimbine or 
the selective $\alpha_{2 \mathrm{C}}$-adrenoceptor antagonist JP1302 also markedly attenuated the initial cold-induced vasoconstriction phase (Fig. 2c-f).

$\alpha_{2 \mathrm{C}}$-adrenoceptors are silent at $37^{\circ} \mathrm{C}$, but in response to cooling, their activity increases as a result of increased reactive oxygen species generation ${ }^{25,26}$. Pretreatment with the highly potent, cell-permeable superoxide dismutase (SOD) mimetic TEMPOL also significantly reduced local cold-induced vasoconstriction (Fig. 2g,h). To determine whether TRPA1 activation induced superoxide release, superoxide levels were

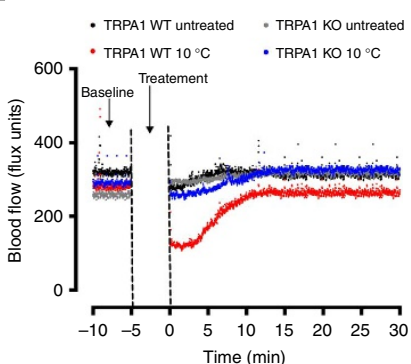

C



e

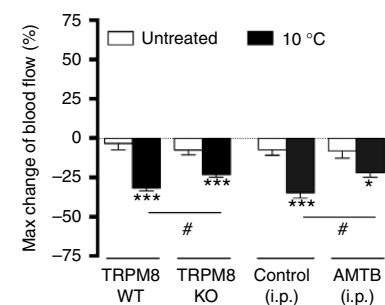

g

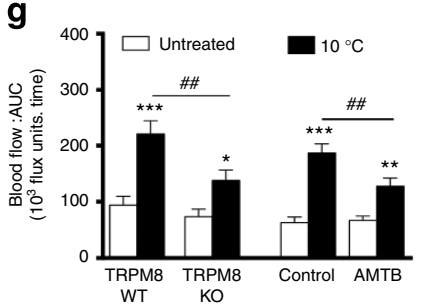

h

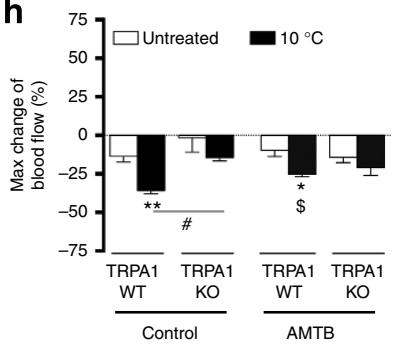

d

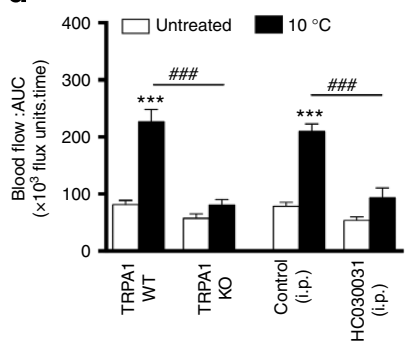

f

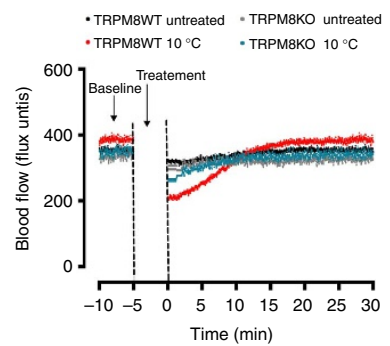

b

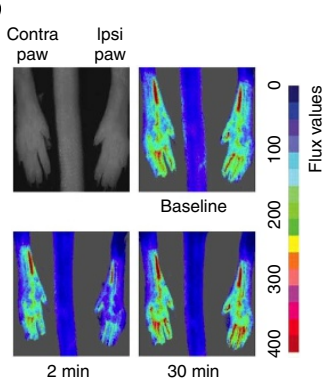

Figure 1 | Cold-induced vascular response is dependent on TRPA1. Blood flow was measured using FLPI in anaesthetized mice following immersion of the ipsilateral hindpaw in cold $\left(10^{\circ} \mathrm{C}\right.$ ) water and contralateral paw remained untreated. (a) Representative blood flow trace of a cold-induced response in WT and TRPA1 KO mice. (b) Representative FLPI pictures alongside grey/black 'photo' showing blood flow at baseline, 2 and $30 \mathrm{~min}$ in cold-treated hindpaw. (c) \% Change in hindpaw blood flow from baseline to $0-2$ min following cold treatment (maximum vasoconstriction) and (d) Restoration of cutaneous blood flow, as assessed by AUC for $30 \mathrm{~min}$ following cold treatment in WT $(n=12)$ and TRPA1 KO $(n=9)$ or WT mice pretreated with TRPA1 antagonist $\mathrm{HC} 030031\left(100 \mathrm{mg} \mathrm{kg}^{-1}\right.$, i.p., $30 \mathrm{~min}$, $n=10$ ) or control (10\% DMSO in saline, i.p., $30 \mathrm{~min}, n=8$ ) before cold treatment. (e) \% Maximum change in hindpaw blood flow from baseline to 0-2 min following cold treatment (maximum vasoconstriction) in WT $(n=10)$ and TRPM8 KO $(n=14)$ mice or WT mice pretreated with TRPM8 antagonist AMTB $\left(10 \mathrm{mg} \mathrm{kg}^{-1}\right.$, i.p., $\left.30 \mathrm{~min}, n=8\right)$ or control $(10 \%$ DMSO in saline, i.p., $30 \mathrm{~min}, n=10$ ) before cold exposure. (f) Representative trace of a cold-induced response in WT and TRPM8 KO mice. (g) Restoration of cutaneous blood flow, assessed by AUC for $30 \mathrm{~min}$ following cold treatment in WT $(n=10)$ and TRPM8 KO $(n=14)$ mice or WT mice pretreated with TRPM8 antagonist AMTB $\left(10 \mathrm{mg} \mathrm{kg}^{-1}\right.$, i.p., $\left.30 \mathrm{~min}, n=8\right)$ or control (10\% DMSO in saline, i.p., $30 \mathrm{~min}, n=10$ ) before cold treatment. (h) \% Change in hindpaw blood flow from baseline to $0-2$ min following cold treatment (maximum vasoconstriction) and (i) Restoration of cutaneous blood flow, assessed by AUC for 30 min following cold treatment in TRPA1 WT $(n=5)$ and KO $(n=5)$ pretreated with control $(10 \%$ DMSO in saline, i.p., $30 \mathrm{~min})$ or TRPA1 WT $(n=4)$ and $\mathrm{KO}(n=4)$ pretreated with AMTB $\left(10 \mathrm{mg} \mathrm{kg}^{-1}\right.$, i.p., $30 \mathrm{~min}$ ). All error bars indicate s.e.m. ${ }^{\star} P<0.05$, ${ }^{\star \star} P<0.01,{ }^{\star \star \star \star} P<0.001$ versus respective untreated, ${ }^{\#} P<0.05,{ }^{\# \# P} P 0.01$, $\# \# P<0.001$ versus cold-treated, $\$ P<0.05$ versus cold-treated TRPA1 WT (analysis of variance, Bonferroni post hoc test). 
observed as a dilator response and analysed as AUC from the maximum of the vasoconstriction phase until the end of the measurement period $(30 \mathrm{~min}$; Fig. 1d). A highly significant

\section{a}

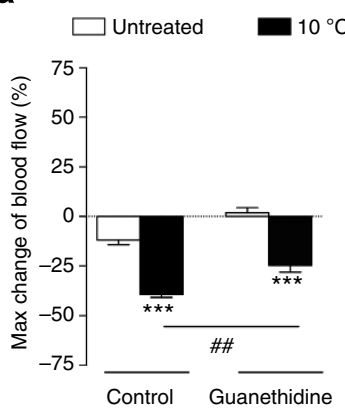

C Control untreated $\cdot$ Yohimbine untreated - Control $10^{\circ} \mathrm{C} \quad \cdot$ Yohimbine $10^{\circ} \mathrm{C}$

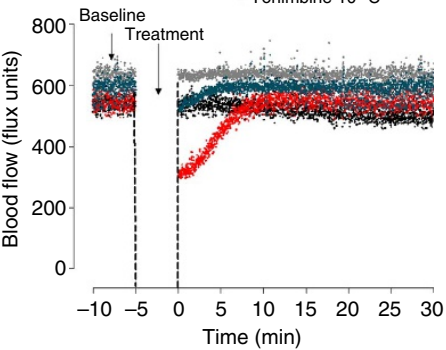

e

- Control untreated $\bullet J P 1302$ untreated - Control $10^{\circ} \mathrm{C} \quad \cdot \mathrm{JP} 130210^{\circ} \mathrm{C}$

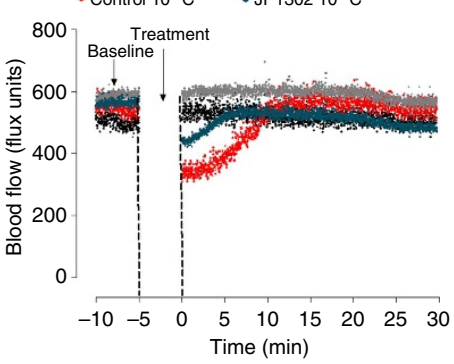

g $\cdot$ Control untreated $\cdot$ TEMPOL untreated - Control $10^{\circ} \mathrm{C} \quad \cdot$ TEMPOL $10^{\circ} \mathrm{C}$
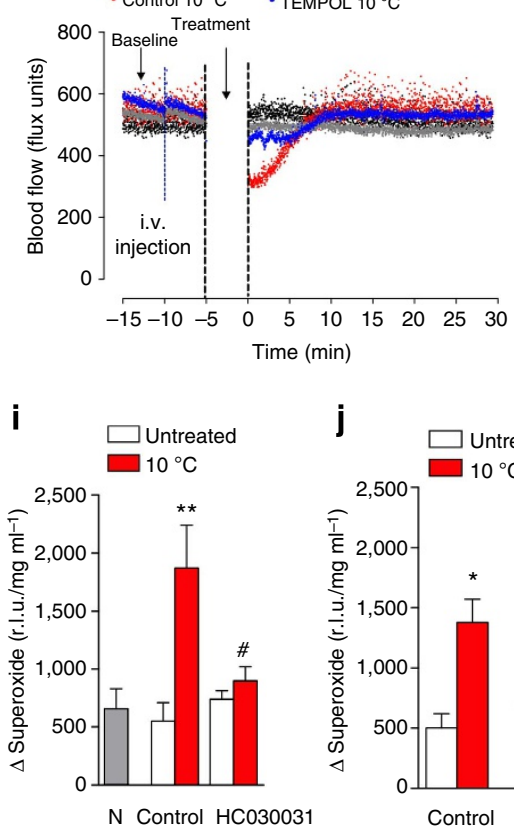

restoration of blood flow was observed in control-treated groups, but not in the absence of the initial constriction response to cold (Fig. 1d). Therefore, neither WT mice treated with HC030031
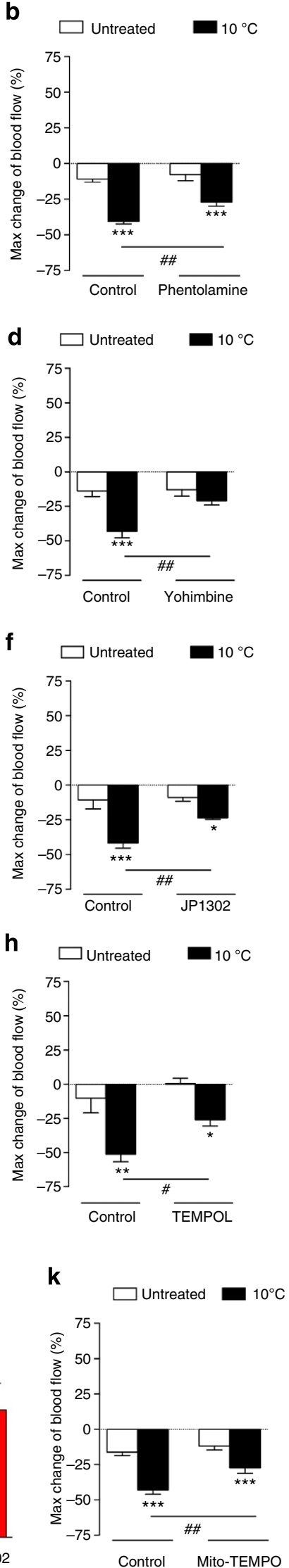
(intraperitoneally, i.p. $30 \mathrm{~min}$ ) before local cold treatment, nor TRPA1 KO mice (Fig. 1d) exhibited this restorative vascular relaxation. Indeed, as this restorative response was not observed in the absence of cold-induced vasoconstriction, it was impossible to assess from these experiments whether TRPA1 was involved in the recovery/dilator component.

Thus, we questioned whether TRPA1 activity was required to initiate the secondary restorative vasodilator phase by examining WT mice treated with the TRPA1 antagonist HC030031 (intravenously, i.v.) during the vasoconstriction phase, following local cold exposure. The results showed that HC030031, administered only once the vasoconstriction had occurred, prevented vasodilatation and as a consequence the return of blood flow to baseline. However, the vasoconstrictor response occurred normally in the respective control groups (Fig. 4a,b). Hence, TRPA1 is pivotal in initiating the vasodilator response, in addition to the vasoconstrictor response following cold exposure. In support of this, chronic treatment with the ultra-potent capsaicin analogue resiniferatoxin to remove the cutaneous sensory nerve component had no effect on the constrictor component (Fig. 4c,d), but significantly inhibited the dilator component, implicating the involvement of sensory neurogenic vasodilation (Fig. 4d,e and Supplementary Fig. 7). The role of TRPA1 as an activator of the sensory neuronal vasodilator axes was further implicated by the finding that pretreatment with the CGRP receptor antagonist BIBN4096 only attenuated the vasodilator component, whilst having no influence on the constrictor component (Fig. 4f,h).

Neuropeptides and nitric oxide in the vasodilator component. The localization of TRPA1 to sensory neurons expressing the neuropeptide CGRP and substance P led us to investigate the involvement of these vasodilators in the cold-induced vascular response. It is known that TRPA1 agonist can mediate an increase in cutaneous blood flow in vivo ${ }^{12,14}$. Pretreatment with the CGRP receptor antagonists $\mathrm{CGRP}_{8-37}$ or BIBN4096 in WT mice caused a significant loss of the cold-induced restorative response (Figs $4 \mathrm{~h}$ and 5a). A similar trend was observed in WT mice pretreated with the substance $\mathrm{P} \quad \mathrm{NK}_{1}$ receptor antagonist SR140333 (Supplementary Fig. 8). Co-treatment with both $\mathrm{CGRP}_{8-37}$ and SR140333 in WT mice did not further inhibit the cold-induced vascular responses (Fig. 5b). Whilst a major involvement of the neuropeptides is clear, the data suggest that other mechanisms are also involved. The classic vasodilator prostaglandins are not involved as the cyclooxygenase inhibitor indomethacin had no effect (Supplementary Fig. 9). By comparison, pretreatment of WT mice with the non-isoform selective nitric oxide synthase (NOS) inhibitor $\mathrm{L}-\mathrm{NAME}$ ( $\mathrm{L}^{\mathrm{G}}$-nitro-L-arginine methyl ester) caused a significant decrease in the response (Supplementary Fig. 10). Moreover, co-treatment with $\mathrm{CGRP}_{8-37}$, SR140333 and L-NAME abolished the cold-induced vascular response (Fig. 5b). Whilst a selective endothelial NOS inhibitor is unavailable, pretreatment with the selective neuronal NOS inhibitor, S-methyl-L-thiocitrulline (SMTC) alone inhibited the coldinduced vascular response (Supplementary Fig. 11) and in combination with the neuropeptide receptor antagonists, the response was substantially attenuated (Fig. 5c). These data highlight that the combined role of vasodilating sensory neuropeptides and NO mediates the recovery of normal blood flow following the initial constrictor response to local cooling.

\section{Discussion}

This study provides evidence that TRPA1 is an essential vascular sensor of cold, playing a primary role in the vascular response to noxious cooling. Development of a murine model of local cooling, which simulates exposure and recovery to local cold and can be modified by pharmacological and genetic means, provides a new insight into the mechanisms underlying cold-induced vascular responses, first discovered in 1930 (ref. 1). The major novel findings are: (1) TRPA1 acts as a vascular cold sensor to 'kick start' the protective cold-induced vascular response as the constrictor response is not observed in the presence of TRPA1 antagonists or in TRPA1 KO mice (2) the initial TRPA1dependent cold-induced vasoconstriction involves TRPM8 and is mediated via stimulation of $\alpha_{2 \mathrm{C}}$-adrenoceptors following superoxide generation and involving Rho-kinase-mediated MLC phosphorylation downstream of TRPA1 activation and (3) the TRPA1-mediated cold-induced restorative vasodilator component of the reflex is mediated by the sensory nervederived neuropeptides CGRP and substance $\mathrm{P}$, and nNOSderived NO following TRPA1 activation.

Physiological human studies have described cold pain perception at low temperatures $\left(<15^{\circ} \mathrm{C}\right)$ (ref. 28). In this study, we established a novel acute cold exposure model to enable the quantitative measurement of vascular responses following the local cooling of the hindpaw of anaesthetised mice. Local cold air exposure $\left(28\right.$ to $\left.5^{\circ} \mathrm{C}\right)$ has been previously demonstrated to reduce blood flow and skin temperature of mouse hindpaw, with reproducible results derived at $10^{\circ} \mathrm{C}$ (ref. 24). Here immediately after local cold water immersion $\left(10^{\circ} \mathrm{C}\right.$ for $\left.5 \mathrm{~min}\right)$, a decrease in

Figure 2 I Sympathetic nerves, $\boldsymbol{\alpha}_{\mathbf{2}}$-adrenoceptors and superoxide in cold-induced vasoconstriction. Blood flow was measured using FLPI in anaesthetized mice following immersion of the ipsilateral hindpaw in cold $\left(10^{\circ} \mathrm{C}\right.$ ) water and the contralateral hindpaw remained untreated. (a) \% Maximum change in hindpaw blood flow from baseline to 0-2 min following cold treatment (maximum vasoconstriction) in WT mice pretreated with guanethidine (30 $\mathrm{mg} \mathrm{kg}^{-1}$, s.c., 4 days, $n=7$ ) or control (saline, s.c., 4 days, $n=7$ ) and (b) WT mice pretreated with the $\alpha$-adrenoceptor antagonist phentolamine (10 $\mathrm{mg} \mathrm{kg}^{-1}$, i.v., $n=6$ ) or control (saline, i.v., $n=6$ ). (c) Representative trace of a cold-induced response and (d) \% Change in hindpaw blood flow from baseline to 0-2 min following cold treatment (maximum vasoconstriction) in WT mice treated with the $\alpha_{2}$-adrenoceptor antagonist

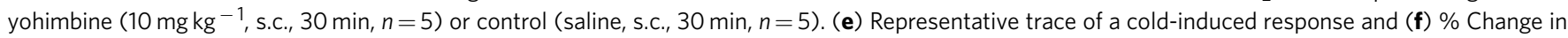
hindpaw blood flow from baseline to 0-2 min following cold treatment (maximum vasoconstriction) in WT mice treated with the $\alpha_{2 \mathrm{C}}$-adrenoceptor antagonist JP1302 (3 $\mu \mathrm{g} \mathrm{kg}^{-1}$, s.c., $60 \mathrm{~min}, n=6$ ) or control (saline, s.c., $60 \mathrm{~min}, n=6$ ). (g) Representative blood flow trace of a cold-induced response and (h) \% Change in blood flow from baseline to 0-2 min following cold treatment (maximum vasoconstriction) in WT mice treated with the SOD mimetic TEMPOL (30 $\mathrm{mg} \mathrm{kg}^{-1}$, i.v., $5 \mathrm{~min}, n=4$ ) or control (saline, i.v., $5 \mathrm{~min}, n=4$ ). Superoxide levels were measured at 2 min (maximum vasoconstriction) following cold treatment in the hindpaw tissue samples by lucigenin chemiluminescence in (i) naïve, WT mice pretreated with TRPA1 antagonist HC030031 (100 $\mathrm{mg} \mathrm{kg}^{-1}$, i.p., $30 \mathrm{~min}$ ) or control (10\% DMSO in saline, i.p., $30 \mathrm{~min}, n=4-5$ ) and (j) WT mice pretreated with JP1302 ( $3 \mu \mathrm{g} \mathrm{kg}-1$, s.c., $\left.60 \mathrm{~min}\right)$ or control (saline, s.c., $30 \mathrm{~min}, n=6-8$ ). (k) \% Change in blood flow from baseline to 0-2 min following cold treatment (maximum vasoconstriction) in WT mice treated with the mitochondria-targeted superoxide scavenger mito-TEMPO (10 mg kg ${ }^{-1}$, i.p., 60 min, $n=9$ ) or control (saline, i.p., 60 min, $n=8$ ). All error bars indicate s.e.m. ${ }^{\star} P<0.05,{ }^{\star \star} P<0.01,{ }^{\star \star \star} P<0.001$ versus respective untreated, ${ }^{\#} P<0.05,{ }^{\# \#} P<0.01$ versus cold-treated hindpaw (analysis of variance, Bonferroni post hoc test). 
a

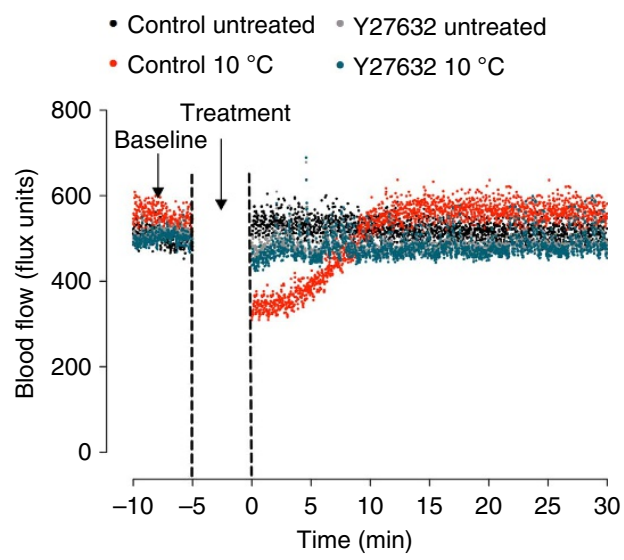

C b
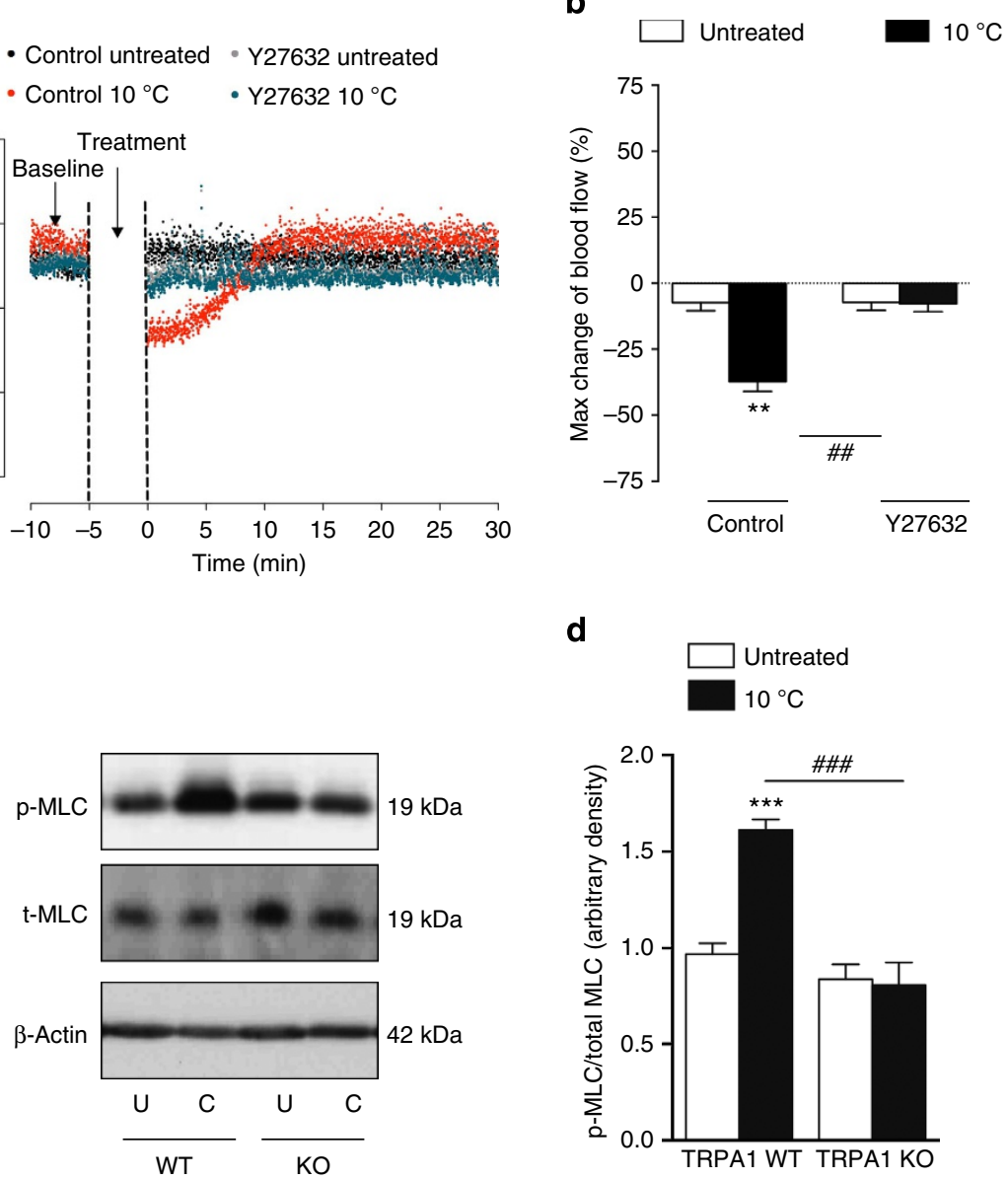

d
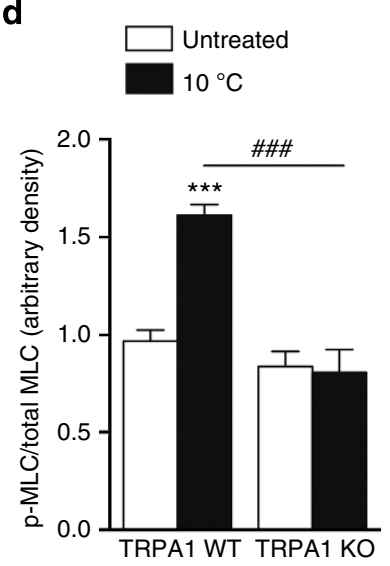

Figure 3 | Rho-kinase-mediated MLC signalling in the cold-induced vasoconstriction. Blood flow was measured using FLPI in anaesthetized mice following immersion of the ipsilateral hindpaw in cold $\left(10^{\circ} \mathrm{C}\right)$ water and the contralateral hindpaw remained untreated. (a) Representative blood flow trace of a cold-induced vascular response in WT mice pretreated with the selective Rho-kinase associated protein kinase inhibitor Y27632 or control (saline). (b) \% Maximum change in hindpaw blood flow from baseline to 0-2 min following local cold treatment (maximum vasoconstriction) in WT mice pretreated with Y27632 (5 mg kg ${ }^{-1}$, i.p., $30 \mathrm{~min}, n=6$ ) and control (saline, i.p., $30 \mathrm{~min}, n=5$ ). (c) Representative western blot of $\mathrm{p}-\mathrm{MLC}$ at Ser ${ }^{19}$ of MLC and total MLC protein expression (uncropped blots are presented in Supplementary Figure 12). (d) Densitometric analysis of p-MLC and total MLC, normalized

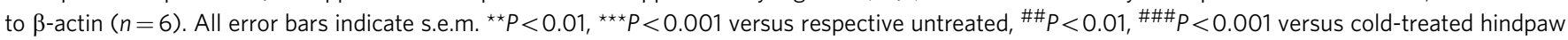
(analysis of variance, Bonferroni post hoc test).

blood flow was observed, followed by a gradual increase in blood flow to restore blood flow to baseline levels, with minimal reflex changes in the untreated hindpaw. The cold-induced vascular response observed in this study did not involve the previously reported Hunting reaction in cold-induced vasodilatation, which is characterized by cyclic oscillations in blood flow induced by subsequent vasoconstrictions and vasodilatations in extremities measured during the active cooling phase ${ }^{1,3}$. We were unable to image blood flow during the actual cooling phase, although we determined a significant vasoconstriction during this phase, through use of a ${ }^{99 m} \mathrm{Tc}$ clearance technique. It is known that excessive vasoconstriction and/or lack of vasodilatation in response to cold or in Raynaud's disease causes tissue hypoxia, and in extreme cold conditions, this can result in cyanosis 4 . Thus, there is an urgent need to fully understand the mechanisms involved.

TRPA1 deletion did not change systemic blood pressure and heart rate, highlighting that TRPA1 does not play a role in regulating baseline blood pressure, although TRPA1 may be involved in cardiovascular autonomic reflexes associated with vasovagal reflexes ${ }^{13}$. Furthermore, TRPA1 antagonists have no effects in altering core body temperature in mice ${ }^{29}$ nor does
TRPA1 act as a thermoregulator ${ }^{30}$. TRPA1 was initially reported as a cold sensor when Story et al. ${ }^{6}$ demonstrated that cold temperatures $\left(<17^{\circ} \mathrm{C}\right)$ induced $\mathrm{Ca}^{2+}$ influx in TRPA1 expressing-Chinese Hamster Ovary cells using $\mathrm{Ca}^{2+}$ imaging studies. Later, Andersson et al. ${ }^{31}$ showed an increase in paw withdrawal latencies in TRPA1 KO mice when placed on a cold plate at $10^{\circ} \mathrm{C}$. The current study was carried out using the same strain of mice. The cold reflex comprising of vasoconstriction followed by restoration of blood flow to baseline levels, (increased blood flow) after exposure of the ipsilateral hind paw to environmental cooling $\left(10^{\circ} \mathrm{C}\right.$ for $\left.5 \mathrm{~min}\right)$ was substantially reduced in TRPA1 KO mice and in WT mice pretreated with the TRPA1 antagonist HC030031. The local nature of the response was confirmed by the finding that blood flow remained relatively stable in the untreated contralateral paw, irrespective of treatment. This provided clear evidence that TRPA1 plays a primary role as a vascular cold sensor.

The role of TRPA1 as a noxious cold pain sensor has been a controversial issue. Studies involving TRPA1 KO mice have yielded conflicting results, where (1) Bautista et al. ${ }^{32}$ showed no change in cold-induced nociceptive responses $\left(-10\right.$ to $\left.-20^{\circ} \mathrm{C}\right)$, (2) Kwan et al..$^{33}$ demonstrated a decrease in cold $\left(0^{\circ} \mathrm{C}\right)$-induced 
pain sensitivity in vivo and (3) there were cold-sensing deficits following prolonged cold exposure in vitro $\left(13^{\circ} \mathrm{C}\right)$ and in cold $\left(0^{\circ} \mathrm{C}\right)$ plate test in vivo ${ }^{9}$. These differences may arise due to the different methodologies used and temperatures studied. However, our present finding that TRPA1 initiates the cold-induced vascular response means that it is possible that changes in blood flow could have influenced the various recordings made and thus contribute to the lack of reproducible findings. a

- Control i.v. untreated $\quad$ HC030031 i.v. untreated

- Control i.v. $10^{\circ} \mathrm{C} \quad$ - HC030031 i.v. $10^{\circ} \mathrm{C}$

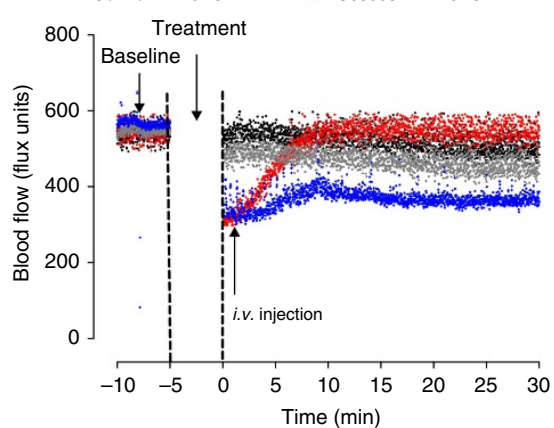

c

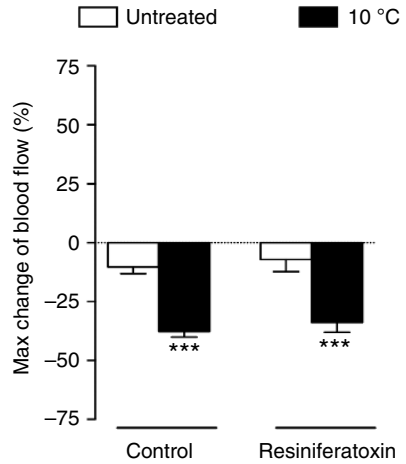

e

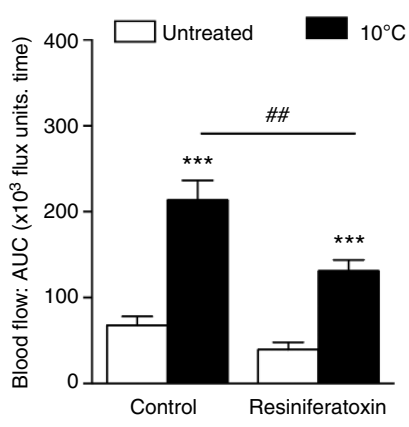

g

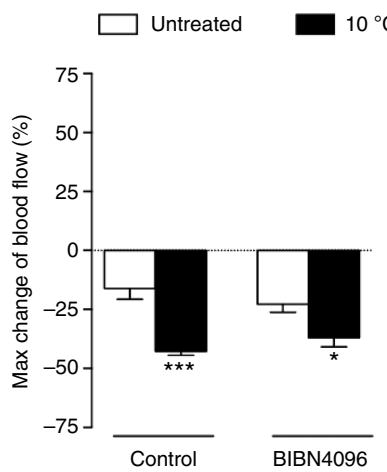

d

$\mathbf{f}$

h b
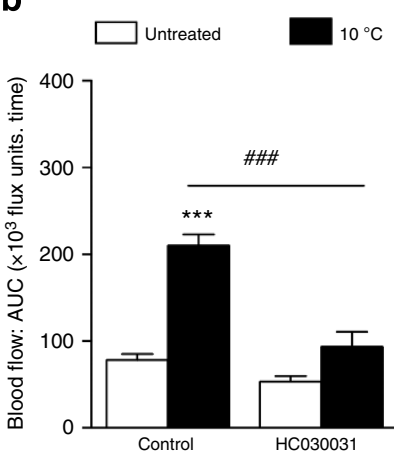

- Control untreated - Resiniferatoxin untreated

- Control $10^{\circ} \mathrm{C} \quad$ Resiniferatoxin $10^{\circ} \mathrm{C}$

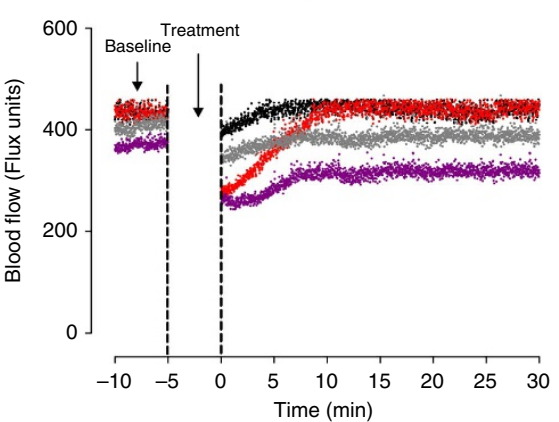

- Control untreated - BIBN4096 untreated

- Control $10^{\circ} \mathrm{C} \quad$ B BIBN4096 $10^{\circ} \mathrm{C}$
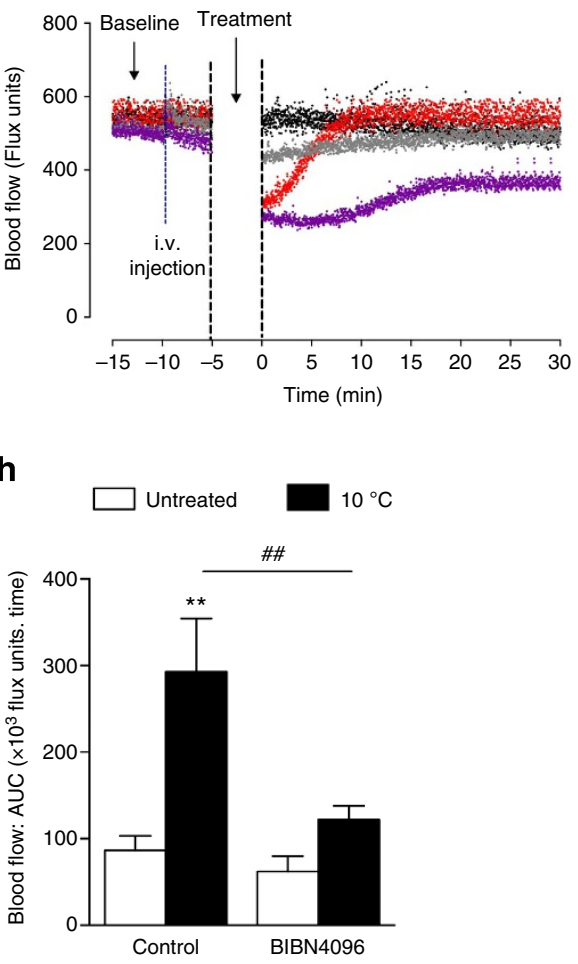
Thermosensitive TRPM8 $\left(<25^{\circ} \mathrm{C}\right)$ is expressed on sensory neurons and mediates the response to deep body cooling which is associated with cutaneous vasoconstriction ${ }^{18}$. TRPM8 is considered to be implicated in thermoregulation as TRPM8 antagonists caused a change in core body temperature in conscious mice and rats ${ }^{18}$. In addition, TRPM8 was shown to override TRPA1 in cold $\left(5-30^{\circ} \mathrm{C}\right)$ detection in neural and behavioral studies in vivo ${ }^{34}$, suggesting that TRPM8 rather than TRPA1 is required for acute cold pain sensing in mammals. In our studies, pharmacological blockade or genetic deletion of TRPM8 caused a significant loss of the cold-induced vascular responses, but to a lesser extent than the pharmacological blockade or genetic deletion of TRPA1. Moreover, a TRPM8 antagonist did not further modify the vascular response in TRPA1 KO mice in our model. This finding provides confirmation that TRPA1 is the primary vascular cold sensor in this model, overriding TRPM8 activity and contrasts with evidence that the selective ablation of TRPM8 neurons in vivo induced a loss of nociceptor sensitivity to both innocuous $\left(17^{\circ} \mathrm{C}\right)$ and noxious $\left(0^{\circ} \mathrm{C}\right)$ cold $^{19}$.

Our findings illustrate a prominent role of TRPA1 in mediating the cold-induced vascular response, whereas a major involvement of sympathetic nerves in mediating cold-induced vasoconstriction is widely accepted ${ }^{35}$. Indeed, sensory and sympathetic nerves have a close overlapping distribution pattern around blood vessels in the periphery and a reciprocal trophic influence was observed following the denervation of either the sensory peptide- or catecholamine-containing sympathetic nerves ${ }^{36}$. Whilst the pharmacological depletion of sympathetic nerves using guanethidine $^{24}$ or blockade of $\alpha$-adrenoceptors using phentolamine had a partial inhibitory effect on the total cold-induced vasoconstriction, we observed a decrease in total noradrenaline concentrations in the cold-treated hindpaw at maximum vasoconstriction in TRPA1 WT but not KO mice, compared to untreated samples. This finding is in agreement with previous studies in plasma from human cold $\left(5^{\circ} \mathrm{C}\right)$ studies ${ }^{37}$ and in cutaneous dog veins $\left(37-28^{\circ} \mathrm{C}\right)$ (ref. 38). The observed changes in noradrenaline concentrations in the paw were TRPA1-dependent, implying an involvement of sympathetic nerves.

Superficial cutaneous vessels exhibit increased responsiveness during cooling ${ }^{35,39}$ and it is established that $\alpha_{1^{-}}$and $\alpha_{2^{-}}$ adrenoceptors mediate peripheral vasoconstriction. All the adrenergic antagonists that we tested exhibited significant effects on the local cold-induced vasoconstriction including the selective $\alpha_{2}$-adrenoceptors antagonist yohimbine, in agreement with previous findings in humans ${ }^{40}$. Different subtypes of $\alpha_{2}$ adrenoceptors are localized in small veins and arteries ${ }^{41}$ and cold treatment has previously been shown to amplify $\alpha_{2 C^{-}}$ adrenoceptors in isolated mouse tail arteries in vitro ${ }^{23}$. We demonstrated that the pharmacological antagonism of $\alpha_{2 C^{-}}$ adrenoceptors using JP1302 caused a significant decrease in the local cold-induced vasoconstriction. $\alpha_{2 \mathrm{C}}$-adrenoceptors are normally silent at thermoneutral temperatures $\left(37^{\circ} \mathrm{C}\right)$, but following cooling $\left(28^{\circ} \mathrm{C}\right)$, they are distributed to the plasma membrane ${ }^{42}$. Although the mechanisms underlying this phenomenon are unclear, both reactive oxygen species and Rho-kinase have been suggested to be involved ${ }^{25}$ and this was directly investigated in vivo during this study. We showed that pretreatment with the SOD mimetic TEMPOL caused a significant decrease in cold-induced vasoconstriction in WT mice, highlighting that TEMPOL may reduce the accumulation of superoxide to water and oxygen in the coldtreated hindpaw, consistent with previous in vitro findings involving the tail artery ${ }^{26}$. We further measured the levels of superoxide in hindpaw tissue samples at the maximum vasoconstriction phase and provided novel evidence showing that cooling induced an increase in total superoxide levels in the cold-treated hindpaw in a TRPA1-dependent manner. This is the first study to highlight an association between TRPA1 activation and superoxide generation following local cooling treatment in vivo. We propose that superoxide is produced downstream of TRPA1 activation by cold exposure in the peripheral vasculature and upstream of $\alpha_{2 C^{-}}$-adrenoceptor activity, as the $\alpha_{2 C^{-}}$ adrenoceptor antagonist JP1302 was able to block constriction, but not superoxide production. Of note, mito-TEMPO inhibited the vasoconstriction, providing evidence that the mitochondria are the cellular source.

Superoxide has been suggested to cause vasoconstriction through the Rho-kinase/ROCK-mediated pathways in the vascular smooth muscle cells ${ }^{25,26}$. Rho-kinase can also be stimulated by noradrenaline and/or superoxide in response to localized cooling ${ }^{26}$. We investigated the role of the Rho-kinasemediated pathways in our cold model. WT mice were pretreated with the selective cell-permeable Rho-kinase inhibitor Y27632, which was previously shown to have no modulatory effects on $\alpha_{2}$ adrenoceptors in vitro in control experiments $\left(37^{\circ} \mathrm{C}\right)$ (ref. 25). Pretreatment with Y27632 completely abolished the cold-induced vasoconstriction at $10^{\circ} \mathrm{C}$, in agreement with previous in vitro cooling $\left(28^{\circ} \mathrm{C}\right)$ studies in mouse tail artery using pressure myography ${ }^{25}$. Hence, our results support previous ex vivo findings and provide new evidence demonstrating that coldinduced vasoconstriction at a lower temperature $\left(10^{\circ} \mathrm{C}\right)$ is dependent on the generation of superoxide following activation of TRPA1, which further leads to activation of Rho-kinase and translocation of $\alpha_{2 \mathrm{C}}$-adrenoceptors to the cell surface membrane for activation in the mouse hindpaws.

Rho-kinase can modulate smooth muscle contraction via an increase in MLC activity ${ }^{27}$. Stimulation of postsynaptic $\alpha_{2}$-adrenoceptors using a selective $\alpha_{2}$-agonist, UK14304 was previously shown to increase vascular tone via an increase in $\left[\mathrm{Ca}^{2+}\right]_{i}$ and MLC phosphorylation in spiral strips of rabbit saphenous vein in vitro ${ }^{43}$. We hypothesized that there was an increase in MLC phosphorylation in the local cold-induced vasoconstriction phase. Indeed, we provide evidence demonstrating

Figure 4 | TRPA1 mediates the vasodilator component of cold-induced responses. Blood flow was measured using FLPI in anaesthetized mice following immersion of the ipsilateral hindpaw in cold $\left(10^{\circ} \mathrm{C}\right.$ ) water and the contralateral hindpaw remained untreated. (a) Representative blood flow trace of a cold-induced vascular response and (b) restoration of cutaneous blood flow, as assessed by AUC for 30 min following cold water immersion in WT mice pretreated with the TRPA1 antagonist $\mathrm{HC} 030031$ ( $6 \mathrm{mg} \mathrm{kg}^{-1}$, i.v., $n=6$ ) or control ( $8 \%$ DMSO in $2 \%$ Tween- 80 in saline, $n=6$ ) at the maximum vasoconstriction phase following local cold water immersion. (c) \% Maximum change in hindpaw blood flow from baseline to 0-2 min following local cold treatment (maximum vasoconstriction), (d) Representative blood flow trace of a cold-induced vascular response and (e) Restoration of cutaneous blood flow, as assessed by AUC for 30 min following cold water immersion in WT mice pretreated with the TRPV1 agonist resiniferatoxin ( 0.3 mg kg ${ }^{-1}$, s.c. daily., 4 days, $n=8$ ) or control ( $10 \%$ ethanol, $10 \%$ Tween- 80 in saline, s.c. daily, 4 days, $n=9$ ). (f) Representative blood flow trace of a cold-induced vascular response, (g) \% Maximum change in hindpaw blood flow from baseline to 0-2 min following local cold treatment (maximum vasoconstriction) and (h) Restoration of cutaneous blood flow, as assessed by AUC for 30 min following cold water immersion in WT mice pretreated with the CGRP receptor antagonist BIBN4096 (0.3 $\mathrm{mg} \mathrm{kg}^{-1}$, i.v., $5 \mathrm{~min}, n=9$ ) or control (saline, i.v., $5 \mathrm{~min}, n=10$ ). All error bars indicate s.e.m. ${ }^{\star} P<0.05,{ }^{\star \star} P<0.01,{ }^{\star \star \star} P<0.001$ versus respective untreated, ${ }^{\#} P<0.01,{ }^{\# \#} P<0.001$ versus cold-treated hindpaw (analysis of variance, Bonferroni post hoc test). 


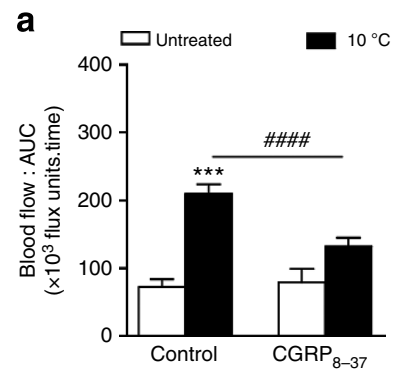

b



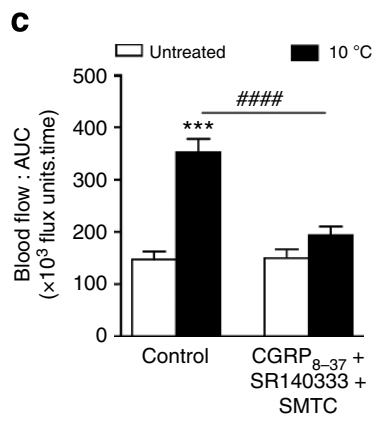



Figure 5 | The cold-induced vascular response is dependent on neuropeptides. Blood flow was measured using FLPI in anaesthetized mice following immersion of the ipsilateral hindpaw in cold $\left(10^{\circ} \mathrm{C}\right)$ water and the contralateral hindpaw remained untreated. Mice were pretreated with pharmacological inhibitors or the respective vehicle (i.v., $5 \mathrm{~min}$ ) before local cold exposure. (a) Effects of CGRP receptor antagonist $\mathrm{CGRP}_{8-37}\left(400 \mathrm{nmol} \mathrm{kg}^{-1}, \mathrm{n}^{-1} 7\right)$ on the cold-induced vascular response in WT mice. (b) Cold-induced vascular response in WT mice pretreated with a combination of CGRP $_{8-37}$ and NK ${ }_{1}$ receptor antagonist SR140333 ( $\left.480 \mathrm{nmol} \mathrm{kg}^{-1}, n=8\right)$ with or without the non-selective NOS inhibitor L-NAME $\left(15 \mathrm{mg} \mathrm{kg}^{-1}, n=7\right)$ and control $(0.01 \%$ BSA in saline, $n=10)$. (c) Effects of CGRP $8-37$, SR140333 and the selective nNOS inhibitor SMTC $\left(10 \mathrm{mg} \mathrm{kg}^{-1}, n=6\right)$ or control (0.01\% BSA in saline, $\left.n=7\right)$ on the cold-induced vascular response in WT mice. All error bars indicate s.e.m. ${ }^{\star} P<0.05,{ }^{\star \star \star} P<0.001,{ }^{\star \star \star \star} P<0.0001$ versus respective untreated,

$\# \# \#<0.001, \# \# \# \#<0.0001$ versus cold-treated hindpaw (analysis of variance, Bonferroni post hoc test). (d) Proposed cold-induced TRPA1 pathway in the regulation of cutaneous vasculature. Local cold exposure $\left(10^{\circ} \mathrm{C}\right)$ causes a transient and rapid decrease in blood flow from baseline $(1)$. This initial phase of cold-induced vasoconstriction consists of activation of TRPA1 which further mediates to (a) the release of noradrenaline (NA) and (b) increased reactive oxygen species release (for example, superoxide $\left(\mathrm{O}_{2}^{-}\right)$generation) that can also activate the ROCK-mediated pathways and increase constriction via

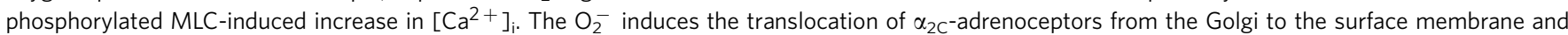
increases adrenergic activity in the VSMC in a ROCK-dependent fashion ${ }^{25}$. (2) The restoration of blood flow following local cold treatment is essential in restoring blood flow to baseline to protect against local cold-induced injuries. This phase is mediated by the release of CGRP, substance $P$ and nitric oxide following TRPA1 activation of sensory neurons. MLC-P, myosin light chain phosphatase; NA, noradrenaline; p-MLC; phosphorylated myosin light chain; VSMC, vascular smooth muscle cell.

that there was an increase in phosphorylated MLC protein in cold-treated hindpaw tissue samples at the maximum vasoconstriction phase of TRPA1 WT but not KO mice. Cumulatively, these findings provide a novel mechanism proposing that local cold exposure activates TRPA1, which causes an increase in superoxide generation, activating Rho-kinase to phosphorylate MLC and/or translocate $\alpha_{2 \mathrm{C}}$-adrenoceptors, ultimately leading to vasoconstriction in the mouse hindpaw.

The role of TRPA1 in mediating vasorelaxant effects is well documented in the literature ${ }^{12,13,15}$, with little evidence of the vascular constrictor activity. Hence, we further determined if endogenous TRPA1 activation was responsible for initiating the restorative phase that follows the constrictor activity in this cold 
model. To determine this, we treated WT mice with HC030031 (i.v.) during the vasoconstriction phase following local cold water immersion. The results showed that although the constrictor phase was able to proceed normally following cold exposure, the acute treatment with the TRPA1 antagonist (i.v.) prevented the vasodilator/recovery phase.

TRPA1 is expressed on sensory neurons and cold-induced responses are known to be controlled neurally ${ }^{1,5,44}$, with conflicting evidence of mechanisms in the literature ${ }^{3}$. Since TRPA1 is co-expressed in TRPV1-positive sensory neurons ${ }^{6,20}$, possible interactions between the two channels may occur. We show that neither pharmacological blockade with two TRPV1 antagonists, nor TRPV1 deletion influenced the cold-induced response. TRPV4 has been suggested to act as an environmental cutaneous thermosensor ${ }^{21}$, but TRPV4 deletion did not affect the response, consistent with the knowledge that there was no change in core body temperature between TRPV4 WT and KO mice following a cold stress $\left(4^{\circ} \mathrm{C} \text { for } 150 \mathrm{~min}\right)^{45}$.

On the other hand, the link between TRPAl and the major sensory neuropeptide dilator CGRP is clear. Our studies using the non-peptide selective antagonist BIBN4096 showed that only the restorative vasodilation phase was affected, which is important in protecting against local cold-induced injury but not the initial constriction component. The pharmacological blockade of either CGRP receptors or the substance $\mathrm{P} \mathrm{NK}_{1}$ receptors caused a significant reduction in the cold-induced restorative response, indicating a key involvement of sensory nerves in this model. A finding was supported here by sensory nerve depletion studies with resiniferatoxin. Whilst we gained no evidence for a role for vasodilator prostaglandins, pretreatment with L-NAME significantly reduced the cold-induced residual vasodilator response, as was observed in previous cooling $\left(4^{\circ} \mathrm{C}\right)$ studies in human skin ${ }^{46}$. A selective endothelial NOS isoform inhibitor is unavailable, but we show that nNOS-derived $\mathrm{NO}$ is involved in mediating the restorative vasodilator response following local skin cold treatment at $10^{\circ} \mathrm{C}$, using the selective nNOS inhibitor SMTC ${ }^{47}$. This is the first study establishing a link between nNOS-derived NO and TRPA1 in mediating vasodilator responses. The pretreatment of mice with a combination of the neuropeptide receptor antagonists and SMTC or L-NAME was able to substantially block the cold-induced blood flow responses, with no significant change in the untreated hindpaw. Thus, there is a clear involvement of the vasodilator sensory neuropeptides and $\mathrm{NO}$ in the cold-induced restorative component. The importance of sensory neurogenic vasodilator responses is unclear; here we provide evidence for their functional importance in restoring cutaneous baseline blood flow to its healthy level, rather than acting in a capacity that leads to obvious increased net blood flow over baseline. This is indicative of a physiologically important role, allowing the restoration of a healthy skin flow, necessary to protect the skin against cold-induced injury. CGRP has been shown to tonically cross-inhibit coldsensitive spinal neurons ${ }^{48}$. We did not observe this in terms of blood flow, just that the normal ability to return to basal blood flow was lost in the absence of functioning neurogenic vasodilation. Whilst the stimulation of sensory nerves with either exogenous TRPA1 or TRPV1 agonists is known to lead to neurogenic vasodilation, the importance of this TRPA1-mediated role of sensory neurogenic vasodilatation in restoring a healthy baseline blood flow to skin has not been defined before. This should be considered as distinct from the increased blood flow commonly observed in response to stimulation of sensory nerves by TRPV1 (for example, flushing in response to the TRPV1 agonist capsaicin).

Collectively, this novel evidence highlights the important role of TRPA1 in (1) sensing the change in temperature at $10^{\circ} \mathrm{C}$,
(2) inducing the initial vasoconstriction phase and (3) stimulating the release of sensory nerve-derived neuropeptides and NO, which are essential in replenishing the blood flow that acts to protect against local cold-induced injury (Fig. 5d). To conclude, we have revealed a primary role of the TRPA1 in orchestrating the vascular response to local cold exposure. This finding is consistent with TRPA1 playing a primary physiological role, as a vascular sensor for noxious cold and that as a consequence is also important for the pathophysiological understanding of peripheral cold injury and disease. The results introduce a new paradigm whereby TRPA1 is an important activation step, acting in two distinct ways to affect the successful vascular protective response to local noxious cold exposure.

\section{Methods}

Animals. Male mice (8-12 weeks of age) were used in all experiments. The initial characterization of cold-induced vascular responses was performed in CD1 mice, purchased from Charles River (Kent, UK). TRPA1 KO mice (C57BL/6-B6129P1/ F2J mixed genetic background) and WT littermates were bred from heterozygotic mice kindly provided by Drs Kelvin Kwan (Harvard Medical School, Boston, MA) and David Corey (Harvard Medical School, Boston, MA) ${ }^{33}$. TRPM8 KO ${ }^{49}$, TRPV1 $\mathrm{KO}^{50}$ and TRPV4 $\mathrm{KO}^{45}$ were raised on a C57/BL6 background and their WT littermates were used as controls. All genetically modified mice were backcrossed for at least eight generations into their respective background. Mice were housed in a climatically controlled environment, on a 12-h light/dark cycle, with free access to water and standard food ad libitum. All experiments were conducted in accordance with the UK Home Office Animals (Scientific Procedures) Act, 1986 and were approved by the King's College London Animal Care and Ethics Committee. All experiments were conducted in a blinded manner. Animals were randomly assigned to control or treatment groups and the experimenter was blinded towards the genetic background of animals at the time of experiment.

Cutaneous blood flow by full-field laser perfusion imager. Mice were anaesthetized i.p. with ketamine $\left(75 \mathrm{mg} \mathrm{kg}^{-1}\right)$ and medetomidine $\left(1 \mathrm{mg} \mathrm{kg}^{-1}\right)$ and cutaneous blood flow was assessed in the whole plantar hindpaw area using the Full-Field Laser Perfusion Imager (FLPI, Moor Instruments, UK) ${ }^{12,14}$. The environmental cooling model consisted of recording baseline blood flow in both hindpaws to ensure the haemodynamic vascular responses have stabilized following anaesthesia. The ipsilateral hindpaw was subsequently exposed up to the level of the joint between the tibia and the calcaneum to cold water $\left(10^{\circ} \mathrm{C}\right.$ for $5 \mathrm{~min})$. The contralateral paw was untreated at room temperature $\left(19-21^{\circ} \mathrm{C}\right)$ and served as a control. Changes in blood flow after these treatments were followed for $30 \mathrm{~min}$. Mice were placed on a heating mat, in the ventral position maintained at $36^{\circ} \mathrm{C}$ for blood flow measurements. The response to cooling consisted of an initial reduced flux, in keeping with vasoconstriction, followed by a slow developing sustained increased flux, consistent with vasodilatation. Water is a much more efficient medium at cooling down tissues and this model allowed blood flow responses to be monitored following the local cooling treatment. Results are expressed as (1) a measure of maximum \% decrease in blood flow from baseline to $0-2 \mathrm{~min}$ following cold treatment or (2) arbitrary flux units $\left(\times 10^{3}\right.$ flux units) measured as area under the recorded flux (response curve) versus time for the entire recording period for $30 \mathrm{~min}$ following cold treatment (Supplementary Fig. 1).

Cutaneous blood flow in the ear by laser Doppler techniques. Skin blood flow was measured concomitantly in both ears of mice anaesthetized with ketamine $\left(75 \mathrm{mg} \mathrm{kg}^{-1}\right)$ and medetomidine $\left(1 \mathrm{mg} \mathrm{kg}^{-1}\right)$ using laser Doppler flowmeter (Moor instruments, UK) and a PowerLab data acquisition system (AD instruments UK) or Full-Field Laser Perfusion Imager (FLPI) ${ }^{13}$. A probe, allowing blood flow to be measured precisely at one point in the ear $\left(1 \mathrm{~mm}^{2}\right.$ and to $1-2 \mathrm{~mm}$ depth), was placed at one point of each ear and a baseline reading was obtained for 2-5 min. Cinnamaldehyde $(20 \mu \mathrm{l}, 10 \%)$ or capsaicin $(200 \mu \mathrm{g}$ solution) was topically applied to the ipsilateral ear and vehicle; $10 \%$ dimethylsulphoxide (DMSO) in ethanol or $100 \%$ ethanol, respectively, on the contralateral ear. Blood flow was subsequently measured for $30 \mathrm{~min}$ (cinnamaldehyde studies) or $20 \mathrm{~min}$ (capsaicin studies), and data collected as flux units that are proportional to blood flow. All experiments using cinnamaldehyde administration was conducted using the laser Doppler flowmeter and in some experiments, images were captured using FLPI, whilst all experiments using capsaicin were conducted using the FLPI. The typical response to cinnamaldehyde or capsaicin involves an initial gradual increase in blood flow from baseline, as a result of vasodilatation. Blood flow data were expressed as area under the recorded flux versus time trace for the entire recording period $(30 \mathrm{~min})$ following topical treatment.

Changes in blood flow by ${ }^{99} \mathrm{~m}$ Tc clearance technique. Blood flow was assessed using a clearance technique in paw tissues ${ }^{51}$. Test agents containing an equal 
amount of radioactive ${ }^{99} \mathrm{~m}_{\text {technetium }}\left({ }^{99 \mathrm{~m}} \mathrm{Tc}\right)$ were prepared immediately before use. Mice were pretreated with control ( $10 \%$ DMSO in saline, i.p., $30 \mathrm{~min})$ or TRPA1 antagonist HC030031 (100 $\mathrm{mg} \mathrm{kg}^{-1}$, i.p., $\left.30 \mathrm{~min}\right)$, anaesthetized with ketamine $\left(75 \mathrm{mg} \mathrm{kg}^{-1}\right)$ and medetomidine $\left(1 \mathrm{mg} \mathrm{kg}^{-1}\right)$ and saline was co-injected with an equal amount of radioactive ${ }^{99 \mathrm{~m}} \mathrm{Tc}$ (20kBq per site, intradermally (i.d.) $30 \mu \mathrm{l}$; Nuclear Medicine, Guy's Hospital, London) in the plantar skin of WT mice. An equal amount of saline $+{ }^{99 \mathrm{~m}} \mathrm{Tc}$ was used as a measurement of total radioactivity. Following i.d. injection, the ipsilateral hindpaw was immersed in local cold water $\left(10^{\circ} \mathrm{C}\right)$ for $5 \mathrm{~min}$ and the contralateral paw remained untreated. At $0-$ 2 min following local cold exposure, the clearance period was terminated by cervical dislocation and death, which reduce blood flow to zero. The paw tissues were rapidly collected and the remaining radioactivity was immediately counted in an adjacent radioactive gamma counter. Clearance was calculated by comparison of the paw tissue and total radioactivity readings. Local cold treatment-specific clearance in the ipsilateral paw was then calculated by comparison with the untreated contralateral paw, normalized to $100 \%$ and expressed as a $\%$ change in clearance compared to the untreated paw. Positive values are due to decreased clearance, which is directly related to decrease blood flow and vasoconstrictor activity.

Radiotelemetry. Blood pressure and heart rate were measured using a radiotelemetry device (PA-C10, DSI, NL), with the catheter placed in the left carotid artery and advanced towards the aortic $\operatorname{arch}^{52}$. It was secured using surgical braided silk (5.0, waxed, Pearsalls sutures) and the outer wound was closed with absorbable sutures (4.0, Ethicon, Johnson and Johnson) in a discontinuous pattern. The transmitter was placed subcutaneously in the left flank and the transmitter pocket was irrigated with sterile saline. All procedures were conducted using aseptic techniques under isoflurane anaesthesia (2.5\%, Abbott Laboratories, UK) in $31 \mathrm{~min}^{-1} \mathrm{O}_{2}$. Surgical anaesthesia was assessed by loss of the paw pinch reflex. Buprenorphine was administered intramuscularly $\left(50 \mu \mathrm{g} \mathrm{kg}^{-1}\right.$, Vetergesic, Alstoe Animal Health) for pain relief. All animals were housed singly and allowed to recover for 7 days before recording baseline blood pressure for three continuous days in a quiet room. Data were collected and calculated by the DSI software (DSI Dataquest A.R.T.) and analysed in Microsoft Excel and GraphPad Prism 5.

Antagonists and inhibitors. The TRPA1 antagonist HC030031 (2-(1,3-dimethyl2,6-dioxo-1,2,3,6-tetrahydro-purin-7-yl)- $N$-(4-isopropyl-phenyl)-acetamide 1) (Tocris, UK) was either dissolved in 10\% DMSO in saline and administered i.p. at a dose of $100 \mathrm{mg} \mathrm{kg}^{-1} 30 \mathrm{~min}^{53}$ before local cold water immersion or in 8\% DMSO, $2 \%$ Tween- 80 in saline and administered i.v. at a dose of $6 \mathrm{mg} \mathrm{kg}^{-1}$ (ref. 54) at the peak vasoconstriction phase $(0-2 \mathrm{~min})$ following local cold water immersion. The TRPM8 antagonist AMTB ( $N$-(3-aminopropyl)-2-[(3-methylphenyl) methyl]oxy$\mathrm{N}$-(2-thienylmethyl)benzamide hydrochloride salt) was dissolved in 10\% DMSO in saline, TRPV1 antagonist SB366791 (4'-Chloro-3-methoxycinnamanilide) in 2\% DMSO in saline or AMG9810 ((2E)- $N$-(2,3-Dihydro-1,4-benzodioxin-6-yl)-3[4-(1,1-dimethylethyl)phenyl]-2-propenamide) (Sigma, UK) in 2\% DMSO and 5\% Tween- 80 in saline and administered at a dose of 10 (ref. 55), 25 (ref. 56) and $50 \mathrm{mg} \mathrm{kg}^{-1}$ (ref. 57), respectively. The CGRP receptor antagonists were dissolved as follows: $\mathrm{CGRP}_{8-37}$ was dissolved in $0.01 \%$ bovine serum albumin (BSA) and administered i.v. at $400 \mathrm{nmol} \mathrm{kg}^{-1}$ (ref. 58) (Tocris,UK). BIBN4096 ((1-piperidinecarboxamide, $N$-[2-[[5-amino-1-[[4-(4-pyridinyl)-1-piperazinyl] carbonyl]pentyl] amino]-1-[3,5-dibromo-4-hydroxyphenyl)methyl]-2-oxoethyl]-4(1,4-dihydro-2-oxo-3(2H)-quinazolinyl)-, $\left[\mathrm{R}^{-}\left(\mathrm{R}^{*}, \mathrm{~S}^{*}\right)\right]$ ) (Tocris, $\left.\mathrm{UK}\right)$ was dissolved in a minimum volume of $1 \mathrm{M} \mathrm{HCl}(0.5 \mathrm{mg}$ per $50 \mu \mathrm{l})$ and the solution was made up to the required final volume with saline at a final stock concentration of $2 \mathrm{mg} \mathrm{ml}^{-1}$, and then titrated with $1 \mathrm{M} \mathrm{NaOH}$ to return the $\mathrm{pH}$ to neutral. BIBN4096 was administered i.v. at $0.3 \mathrm{mg} \mathrm{kg}^{-1}$ (refs 59,60). The $\mathrm{NK}_{1}$ receptor antagonist SR140333 ((S)1-(2-[3-(3,4-dichlorophnyl)-1-(3-isopropoxyphenylacetyl)piperidin-3-yl] ethyl)-4-phenyl-1-azoniabicyclo[2.2.2] octane chloride) ${ }^{60}$, a gift from Dr X. Emonds-Alt, Sanofi, Toulouse, France, was dissolved in saline and administered at a dose of $480 \mathrm{nmol} \mathrm{kg}{ }^{-1}$ i.v. The non-selective NOS inhibitor L-NAME ${ }^{60}$ or the selective nNOS inhibitor SMTC (Sigma, UK) was dissolved in saline and administered i.v. at $15 \mathrm{mg} \mathrm{kg}^{-1}$ (ref. 61). The cyclooxygenase inhibitor indomethacin (Sigma, UK) was dissolved in $5 \% \mathrm{NaHCO}_{3}$ in saline and administered i.v. at $20 \mathrm{mg} \mathrm{kg}^{-1}$ (ref. 60). The non-selective $\alpha$-adrenoceptor antagonist phentolamine ${ }^{2}$ was dissolved in saline and administered i.v. at a dose of $10 \mathrm{mg} \mathrm{kg}^{-1}$, whilst the sympathetic nerve blocker guanethidine ${ }^{63}$ (Sigma, UK) was dissolved in saline and administered subcutaneously (s.c.), at a dose of $30 \mathrm{mg} \mathrm{kg}^{-1}$ daily for four consecutive days. The $\alpha_{2}$-adrenoceptor antagonist yohimbine hydrochloride, the selective $\alpha_{2 \mathrm{C}}$-adrenoceptor antagonist JP1302 dihydrochloride and the selective Rho-associated protein kinase (ROCK) inhibitor Y27632 (Tocris, UK) were dissolved in saline and administered at a dose of $10 \mathrm{mg} \mathrm{kg}^{-1}$ (i.p. $)^{64}$, $3 \mu \mathrm{g} \mathrm{kg}^{-1}$ (s.c. $)^{65}$ or $5 \mathrm{mg} \mathrm{kg}^{-1}$ (i.p. $)^{66}$, respectively. The SOD mimetic TEMPOL was dissolved in saline and administered i.v. at a dose of $30 \mathrm{mg} \mathrm{kg}^{-1}$ (ref. 60), whilst the mitochondria-targeted superoxide scavenger mito-TEMPO was dissolved in saline and administered i.p. at a dose of $10 \mathrm{mg} \mathrm{kg}^{-1}$ (ref. 67). The capsaicin analogue resiniferatoxin was dissolved in 10\% ethanol, 10\% Tween- 80 in saline and administered s.c. at a dose of $0.3 \mathrm{mg} \mathrm{kg}^{-1}$ for three consecutive days ${ }^{68}$. These drugs were administered i.v. $5 \mathrm{~min}$, i.p. $30 \mathrm{~min}$ and s.c. $60 \mathrm{~min}$ before baseline blood flow recording. The doses used were based on previous and preliminary studies.

Superoxide measurements. Superoxide release from fresh plantar hindpaw skin samples was measured by chemiluminescence using lucigenin (bis- $\mathrm{N}$-methylacridinium nitrate; Sigma Aldrich) as a probe. Chemiluminescense was measured using a GloMax 20/20 luminometer (Promega, UK). Skin samples were collected 0-2 min post cold water immersion, which corresponds to the peak vasoconstriction phase of the cold-induced vascular response, as determined by laser speckle imaging studies. The samples were placed in $100 \mu \mathrm{l}$ of modified Krebs' buffer (composition of $131 \mathrm{mM} \mathrm{NaCl}, 5.6 \mathrm{mM} \mathrm{KCl}, 25 \mathrm{mM} \mathrm{NaHCO}, 1 \mathrm{mM} \mathrm{NaH}_{2} \mathrm{PO}_{4} \cdot \mathrm{H}_{2} \mathrm{O}, 5 \mathrm{mM}$ glucose, $5 \mathrm{mM}$ HEPES, $100 \mu \mathrm{M}$ L-arginine, $2.5 \mathrm{mM} \mathrm{CaCl}_{2}, 1 \mathrm{mM} \mathrm{MgCl}_{2}$ and $100 \mu \mathrm{M}$ NADPH, pH7.4) and a further $100 \mu \mathrm{l}$ of modified Krebs' buffer containing lucigenin $(10 \mathrm{mM})$ and NADPH $(500 \mu \mathrm{M})$ was added to each sample with or without SOD $\left(50 \mathrm{U} \mathrm{ml}^{-1}\right)$. Chemiluminescense was recorded after $4 \mathrm{~min}$. Results are expressed as the difference in the relative light units per $\mathrm{mg}$ of protein in the presence and absence of SOD after subtraction of background luminescence ${ }^{69}$.

Western blotting. Plantar hindpaw skin tissues of TRPA1 WT and KO mice were collected 0-2 min post cold water immersion and snap frozen at $-80^{\circ} \mathrm{C}$ until processing. Tissue was then lysed using in SDS lysis buffer containing protease (one tablet per $50 \mathrm{ml}$, Roche, Germany) and phosphatase (one tablet per ml, Roche, Germany) inhibitor. Lysates were clarified by centrifuging at 2,600 $\mathrm{g}$ for $10 \mathrm{~min}$ at $4^{\circ} \mathrm{C}$. Protein concentration was assessed using the Bradford dye-binding method kit (Bio-rad). Protein $(30 \mu \mathrm{g})$ was loaded and separated by SDS-polyacrylamide gel electrophoresis and transferred to polyvinylidene difluoride membranes using a semi-dry technique. Membranes were blocked with 5\% BSA in Tris-buffered saline (TBS) and $0.1 \%$ Tween and incubated with primary antibodies against MLC-2 ( $\mathrm{t}$ MLC, 1:500 dilution, Cell Signaling, UK, \#3672) and phospho-MLC (Ser19, 1:500 dilution, Cell Signaling, UK, \#3671) in 5\% BSA in TBS and 0.1\% Tween for $16 \mathrm{~h}$ at $4{ }^{\circ} \mathrm{C}$. Membranes were washed further with TBS $0.1 \%$ Tween and incubated with a horseradish peroxidase conjugated anti-rabbit secondary antibody (1:2,000 dilution, Sigma, UK, \#AP132P). Proteins were detected by enhanced chemiluminescence (ECL, Piercenet, UK) and developed using the Syngene gel doc dark room system (Chicago, USA). Densitometric analysis performed using Image J analysis software (NIH, USA). MLC phosphorylation was assessed by calculating the ratio of anti-phosphorylated-MLC signal to anti-total MLC signal with defined regions, normalized to the loading control $\beta$-actin (1:2,000 dilution, Sigma, UK, \#A1978). Uncropped images of immunoblots are shown in Supplementary Fig. 12.

Quantification of noradrenaline using ELISA. Noradrenaline levels were measured using a commercially available Noradrenaline Enzyme Linked Immuno Sorbent Assay (ELISA) kit (RE59261; IBL International, Hamburg, Germany) in hindpaw tissue homogenates of WT and TRPA1 KO mice following cold treatment at $0-2 \mathrm{~min}$. Samples were collected in a sterile environment and snapfrozen at $-80^{\circ} \mathrm{C}$ until processing. Tissue samples were homogenized in RIPA lysis buffer (Sigma, UK) containing protease inhibitors (one tablet per $50 \mathrm{ml}$, Roche, Germany) and lysates were clarified by centrifuging at $2,600 \mathrm{~g}$ for $10 \mathrm{~min}$ at $4{ }^{\circ} \mathrm{C}$. According to the manufacturer's instructions, $20 \mu \mathrm{l}$ of tissue lysates, standards and controls were added to extraction plates. After extraction, bound noradrenaline $(25 \mu \mathrm{l})$ was eluted using release buffer and transferred to a 96-well ELISA plate. Noradrenaline antiserum $(50 \mu \mathrm{l})$ was incubated with all samples at room temperature for $120 \mathrm{~min}$ on an orbital shaker; the plates were thoroughly washed with diluted washing buffer and $100 \mu \mathrm{l}$ of enzyme conjugate was added into each well and incubated for $60 \mathrm{~min}$ at room temperature. Following several washes, $200 \mu \mathrm{l}$ of pNPP substrate solution was incubated at room temperature for $40 \mathrm{~min}$ and the reactions were stopped by addition of $50 \mu \mathrm{l}$ of pNPP stop solution per well. The optical density of each well was measured at $405 \mathrm{~nm}$ and a standard curve was plotted using a range of known noradrenaline concentrations provided in the kit $(0,5,15,50,150$, $500 \mathrm{ng} \mathrm{ml}^{-1}$ ). Positive and negative controls were included to determine accuracy. The limit of sensitivity was $20 \mathrm{pg} \mathrm{ml}^{-1}$ and the linearity limit was $8.0 \mathrm{ng} \mathrm{ml}^{-1}$. Cross-reactivity to other catecholamines or metabolites was manufacturer tested as $<0.02 \%$. Protein concentrations of each sample was determined using the Bradford dye-binding method (Bio-rad) and noradrenaline concentrations of each sample was normalized to $\mathrm{mg}$ of protein and expressed as noradrenaline $\left(\mathrm{ng} \mathrm{mg}^{-1}\right.$ tissue protein $)^{70}$

Statistical analysis. Most experiments in this study involved four groups and hence, a power analysis for a two-way analysis of variance design was used, based on previously published data from the mouse ear model and hindpaw vasculature 12,13 . For confidence at the $0.05(5 \%)$ with power at $0.8(80 \%)$ and the effect size of medium (0.75), groups of $n=8$ are recommended. In some experiments where a difference was clearly distinct, the experiment was unblinded for analysis (sample size $>4$ ) to minimize animal use.

Results are expressed as mean \pm s.e.m. Data statistical analysis was performed using a two-tailed Student's $t$-test or two-way analysis of variance followed by Bonferroni's comparison post hoc test. $P<0.05$ was considered to represent a significant difference. 


\section{References}

1. Lewis, T. Observations upon the reactions of the vessels of the human skin to cold. Heart 15, 177-208 (1930).

2. Keatinge, W. R. The effect of general chilling on the vasodilator response to cold. J. Physiol. 139, 497-507 (1957).

3. Daanen, H. A. Finger cold-induced vasodilation: a review. Eur. J. Appl. Physiol. 89, 411-426 (2003).

4. Brain, S. D., Petty, R. G., Lewis, J. D. \& Williams, T. J. Cutaneous blood flow responses in the forearms of Raynaud's patients induced by local cooling and intradermal injections of CGRP and histamine. Br. J. Clin. Pharmacol. 30, 853-859 (1990).

5. Johnson, J. M., Yen, T. C., Zhao, K. \& Kosiba, W. A. Sympathetic, sensory, and nonneuronal contributions to the cutaneous vasoconstrictor response to local cooling. Am. J. Physiol. Heart Circ. Physiol. 288, H1573-H1579 (2005).

6. Story, G. M. et al. ANKTM1, a TRP-like channel expressed in nociceptive neurons, is activated by cold temperatures. Cell 112, 819-829 (2003).

7. del Camino, D. et al. TRPA1 contributes to cold hypersensitivity. J. Neurosci. 30, 15165-15174 (2010).

8. Gentry, C., Stoakley, N., Andersson, D. A. \& Bevan, S. The roles of iPLA2, TRPM8 and TRPA1 in chemically induced cold hypersensitivity. Mol. Pain 6, 4 (2010).

9. Karashima, Y. et al. TRPA1 acts as a cold sensor in vitro and in vivo. Proc. Natl Acad. Sci. USA 106, 1273-1278 (2009).

10. Obata, K. et al. TRPA1 induced in sensory neurons contributes to cold hyperalgesia after inflammation and nerve injury. J. Clin. Invest. 115, 2393-2401 (2005).

11. Bodkin, J. V. \& Brain, S. D. Transient receptor potential ankyrin 1: emerging pharmacology and indications for cardiovascular biology. Acta Physiol. 203, 87-98 (2011).

12. Graepel, R. et al. 4-oxo-2-nonenal (4-ONE): evidence of transient receptor potential ankyrin 1-dependent and -independent nociceptive and vasoactive responses in vivo. J. Pharmacol. Exp. Ther. 337, 117-124 (2011).

13. Pozsgai, G. et al. Evidence for the pathophysiological relevance of TRPA1 receptors in the cardiovascular system in vivo. Cardiovasc. Res. 87, 760-768 (2010).

14. Grant, A. D., Pinter, E., Salmon, A. M. \& Brain, S. D. An examination of neurogenic mechanisms involved in mustard oil-induced inflammation in the mouse. Eur. J. Pharmacol. 507, 273-280 (2005).

15. Earley, S., Gonzales, A. L. \& Crnich, R. Endothelium-dependent cerebral artery dilation mediated by TRPA1 and Ca2 + -Activated $\mathrm{K}+$ channels. Circ. Res. 104, 987-994 (2009).

16. Earley, S. Endothelium-dependent cerebral artery dilation mediated by transient receptor potential and $\mathrm{Ca} 2+$-activated $\mathrm{K}+$ channels. J. Cardiovasc. Pharmacol. 57, 148-153 (2011).

17. McKemy, D. D., Neuhausser, W. M. \& Julius, D. Identification of a cold receptor reveals a general role for TRP channels in thermosensation. Nature 416, 52-58 (2002).

18. Almeida, M. C. et al. Pharmacological blockade of the cold receptor TRPM8 attenuates autonomic and behavioral cold defenses and decreases deep body temperature. J. Neurosci. 32, 2086-2099 (2012).

19. Knowlton, W. M. et al. A sensory-labeled line for cold: TRPM8-expressing sensory neurons define the cellular basis for cold, cold pain, and coolingmediated analgesia. J. Neurosci. 33, 2837-2848 (2013).

20. Kobayashi, K. et al. Distinct expression of TRPM8, TRPA1, and TRPV1 mRNAs in rat primary afferent neurons with adelta/c-fibers and colocalization with trk receptors. J. Comp. Neurol. 493, 596-606 (2005).

21. Nagai, K., Saitoh, Y., Saito, S. \& Tsutsumi, K. Structure and hibernationassociated expression of the transient receptor potential vanilloid 4 channel (TRPV4) mRNA in the Japanese grass lizard (Takydromus tachydromoides). Zoolog. Sci. 29, 185-190 (2012).

22. Watanabe, H. et al. Heat-evoked activation of TRPV4 channels in a HEK293 cell expression system and in native mouse aorta endothelial cells. J. Biol. Chem. 277, 47044-47051 (2002).

23. Chotani, M. A., Flavahan, S., Mitra, S., Daunt, D. \& Flavahan, N. A. Silent alpha(2C)-adrenergic receptors enable cold-induced vasoconstriction in cutaneous arteries. Am. J. Physiol. Heart Circ. Physiol. 278, H1075-H1083 (2000).

24. Honda, M., Suzuki, M., Nakayama, K. \& Ishikawa, T. Role of alpha2Cadrenoceptors in the reduction of skin blood flow induced by local cooling in mice. Br. J. Pharmacol. 152, 91-100 (2007).

25. Bailey, S. R., Eid, A. H., Mitra, S., Flavahan, S. \& Flavahan, N. A. Rho kinase mediates cold-induced constriction of cutaneous arteries: role of alpha2Cadrenoceptor translocation. Circ. Res. 94, 1367-1374 (2004).

26. Bailey, S. R., Mitra, S., Flavahan, S. \& Flavahan, N. A. Reactive oxygen species from smooth muscle mitochondria initiate cold-induced constriction of cutaneous arteries. Am. J. Physiol. Heart Circ. Physiol. 289, H243-H250 (2005).

27. Somlyo, A. P. \& Somlyo, A. V. Ca2 + sensitivity of smooth muscle and nonmuscle myosin II: modulated by $\mathrm{G}$ proteins, kinases, and myosin phosphatase. Physiol. Rev. 83, 1325-1358 (2003).
28. Morin, C. \& Bushnell, M. C. Temporal and qualitative properties of cold pain and heat pain: a psychophysical study. Pain 74, 67-73 (1998).

29. Chen, J. et al. Selective blockade of TRPA1 channel attenuates pathological pain without altering noxious cold sensation or body temperature regulation. Pain 152, 1165-1172 (2011)

30. Trevisan, G. et al. TRPA1 receptor stimulation by hydrogen peroxide is critical to trigger hyperalgesia and inflammation in a model of acute gout. Free. Radic. Biol. Med. 72, 200-209 (2014).

31. Andersson, D. A., Gentry, C., Moss, S. \& Bevan, S. Transient receptor potential A1 is a sensory receptor for multiple products of oxidative stress. J. Neurosci. 28, 2485-2494 (2008).

32. Bautista, D. M. et al. TRPA1 mediates the inflammatory actions of environmental irritants and proalgesic agents. Cell 124, 1269-1282 (2006).

33. Kwan, K. Y. et al. TRPA1 contributes to cold, mechanical, and chemical nociception but is not essential for hair-cell transduction. Neuron 50, 277-289 (2006).

34. Knowlton, W. M., Bifolck-Fisher, A., Bautista, D. M. \& McKemy, D. D. TRPM8, but not TRPA1, is required for neural and behavioral responses to acute noxious cold temperatures and cold-mimetics in vivo. Pain 150, 340-350 (2010).

35. Gardner, C. A. \& Webb, R. C. Cold-induced vasodilatation in isolated, perfused rat tail artery. Am. J. Physiol. 251, H176-H181 (1986).

36. Terenghi, G., Zhang, S. Q., Unger, W. G. \& Polak, J. M. Morphological changes of sensory CGRP-immunoreactive and sympathetic nerves in peripheral tissues following chronic denervation. Histochemistry 86, 89-95 (1986).

37. Nakamoto, M. Responses of sympathetic nervous system to cold exposure in vibration syndrome subjects and age-matched healthy controls. Int. Arch. Occup. Environ. Health 62, 177-181 (1990).

38. Vanhoutte, P. M. \& Verbeuren, T. J. Depression by local cooling of $3 \mathrm{H}$-norepinephrine release evoked by nerve stimulation in cutaneous veins. Blood Vessels 13, 92-99 (1976).

39. Janssens, W. J., Verbeuren, T. J. \& Vanhoutte, P. M. Effect of moderate cooling on adrenergic neuroeffector interaction in canine cutaneous veins. Blood Vessels 18, 281-295 (1981).

40. Cooke, J. P. \& Marshall, J. M. Mechanisms of Raynaud's disease. Vasc. Med. 10, 293-307 (2005).

41. Faber, J. E. Effect of local tissue cooling on microvascular smooth muscle and postjunctional alpha 2-adrenoceptors. Am. J. Physiol. 255, H121-H130 (1988).

42. Jeyaraj, S. C. et al. Cooling evokes redistribution of alpha2C-adrenoceptors from Golgi to plasma membrane in transfected human embryonic kidney 293 cells. Mol. Pharmacol. 60, 1195-1200 (2001).

43. Aburto, T. K., Lajoie, C. \& Morgan, K. G. Mechanisms of signal transduction during alpha 2-adrenergic receptor-mediated contraction of vascular smooth muscle. Circ. Res. 72, 778-785 (1993).

44. Hodges, G. J. et al. Role of sensory nerves in the cutaneous vasoconstrictor response to local cooling in humans. Am. J. Physiol. Heart Circ. Physiol. 293, H784-H789 (2007).

45. Liedtke, W. \& Friedman, J. M. Abnormal osmotic regulation in trpv4 - / mice. Proc. Natl Acad. Sci. USA 100, 13698-13703 (2003).

46. Yamazaki, F. et al. Rate dependency and role of nitric oxide in the vascular response to direct cooling in human skin. J. Appl. Physiol. 100, 42-50 (2006).

47. Kajekar, R., Gupta, P., Shepperson, N. B. \& Brain, S. D. Effect of a 5-HT1 receptor agonist, CP-122,288, on oedema formation induced by stimulation of the rat saphenous nerve. Br. J. Pharmacol. 115, 1-2 (1995).

48. McCoy, E. S. et al. Peptidergic CGRPalpha primary sensory neurons encode heat and itch and tonically suppress sensitivity to cold. Neuron 78, 138-151 (2013).

49. Bautista, D. M. et al. The menthol receptor TRPM8 is the principal detector of environmental cold. Nature 448, 204-208 (2007).

50. Caterina, M. J. et al. Impaired nociception and pain sensation in mice lacking the capsaicin receptor. Science 288, 306-313 (2000).

51. Sawyer, I. et al. The vasoactive potential of kisspeptin-10 in the peripheral vasculature. PLoS ONE 6, e14671 (2011).

52. Marshall, N. J. et al. A role for TRPV1 in influencing the onset of cardiovascular disease in obesity. Hypertension 61, 246-252 (2013).

53. McNamara, C. R. et al. TRPA1 mediates formalin-induced pain. Proc. Natl Acad. Sci. USA 104, 13525-13530 (2007).

54. Andrade, E. L. et al. TRPA1 receptor modulation attenuates bladder overactivity induced by spinal cord injury. Am. J. Physiol. Renal Physiol. 300, F1223-F1234 (2011).

55. Lashinger, E. S. et al. AMTB, a TRPM8 channel blocker: evidence in rats for activity in overactive bladder and painful bladder syndrome. Am. J. Physiol. Renal Physiol. 295, F803-F810 (2008).

56. Gunthorpe, M. J. et al. Identification and characterisation of SB-366791, a potent and selective vanilloid receptor (VR1/TRPV1) antagonist. Neuropharmacology 46, 133-149 (2004). 
57. Gavva, N. R. et al. AMG 9810 [(E)-3-(4-t-butylphenyl)-N-(2,3-dihydrobenzo [b] 11,4$]$ dioxin-6-yl)acrylamide], a novel vanilloid receptor 1 (TRPV1) antagonist with antihyperalgesic properties. J. Pharmacol. Exp. Ther. 313, 474484 (2005).

58. Fernandes, E. S. et al. A distinct role for transient receptor potential ankyrin 1, in addition to transient receptor potential vanilloid 1 , in tumor necrosis factor alpha-induced inflammatory hyperalgesia and Freund's complete adjuvantinduced monarthritis. Arthritis Rheum. 63, 819-829 (2011).

59. Doods, H. et al. Pharmacological profile of BIBN4096BS, the first selective small molecule CGRP antagonist. Br. J. Pharmacol. 129, 420-423 (2000).

60. Starr, A. et al. A reactive oxygen species-mediated component in neurogenic vasodilatation. Cardiovasc. Res. 78, 139-147 (2008).

61. Gozal, D., Torres, J. E., Gozal, Y. M. \& Littwin, S. M. Effect of nitric oxide synthase inhibition on cardiorespiratory responses in the conscious rat. J. Appl. Physiol. (1985) 81, 2068-2077 (1996).

62. Koganezawa, T. et al. Local regulation of skin blood flow during cooling involving presynaptic P2 purinoceptors in rats. $\mathrm{Br}$. J. Pharmacol. 148, 579-586 (2006).

63. Neil, A., Attal, N. \& Guilbaud, G. Effects of guanethidine on sensitization to natural stimuli and self-mutilating behaviour in rats with a peripheral neuropathy. Brain Res. 565, 237-246 (1991).

64. van Oene, J. C., de Vries, J. B. \& Horn, A. S. The effectiveness of yohimbine in blocking rat central dopamine autoreceptors in vivo. Naunyn Schmiedeberg's Arch. Pharmacol. 327, 304-311 (1984).

65. Sallinen, J. et al. Pharmacological characterization and CNS effects of a novel highly selective alpha2C-adrenoceptor antagonist JP-1302. Br. J. Pharmacol. 150, 391-402 (2007).

66. Buyukafsar, K. et al. Rho-kinase inhibitor, Y-27632, has an antinociceptive effect in mice. Eur. J. Pharmacol. 541, 49-52 (2006).

67. Patil, N. K., Parajuli, N., MacMillan-Crow, L. A. \& Mayeux, P. R. Inactivation of renal mitochondrial respiratory complexes and manganese superoxide dismutase during sepsis: mitochondria-targeted antioxidant mitigates injury. Am. J. Physiol. Renal Physiol. 306, F734-F743 (2014).

68. Russell, F. A., Fernandes, E. S., Courade, J. P., Keeble, J. E. \& Brain, S. D. Tumour necrosis factor alpha mediates transient receptor potential vanilloid 1-dependent bilateral thermal hyperalgesia with distinct peripheral roles of interleukin-1beta, protein kinase $\mathrm{C}$ and cyclooxygenase-2 signalling. Pain 142, 264-274 (2009).

69. Fernandes, E. S. et al. Superoxide generation and leukocyte accumulation: key elements in the mediation of leukotriene $\mathrm{B}(4)$-induced itch by transient receptor potential ankyrin 1 and transient receptor potential vanilloid 1. FASEB J. 27, 1664-1673 (2013).

70. Westermann, J., Hubl, W., Kaiser, N. \& Salewski, L. Simple, rapid and sensitive determination of epinephrine and norepinephrine in urine and plasma by noncompetitive enzyme immunoassay, compared with HPLC method. Clin. Lab. 48, 61-71 (2002)

\section{Acknowledgements}

We are grateful to Nayaab A. Kader for technical assistance and Pratish Thakore for help with illustrations. This work was supported by the British Heart Foundation and a Capacity Building Award in Integrative Mammalian Biology. It was also supported by Arthritis Research UK and XK is supported by a British Pharmacological Society AJ Clark studentship.

\section{Author contributions}

A.A.A. and R.G. characterized the model, performed and analysed data and wrote the manuscript; X.K., K.M.A., J.V.B., S.S., C.G., R.H. and E.S.F. performed the experiments and data analysis; A.D.G. and S.J.B. provided the reagents and advice on analysis. S.D.B. coordinated the project, drafted and wrote the article. All authors contributed to the final version.

\section{Additional information}

Supplementary Information accompanies this paper at http://www.nature.com/ naturecommunications

Competing financial interests: The authors declare no competing financial interests.

Reprints and permission information is available online at http://npg.nature.com/ reprintsandpermissions/

How to cite this article: Aubdool, A. A. et al. TRPA1 is essential for the vascular response to environmental cold exposure. Nat. Commun. 5:5732 doi: $10.1038 /$ ncomms6732 (2014)



This work is licensed under a Creative Commons Attribution 4.0 International License. The images or other third party material in this article are included in the article's Creative Commons license, unless indicated otherwise in the credit line; if the material is not included under the Creative Commons license, users will need to obtain permission from the license holder to reproduce the material. To view a copy of this license, visit http://creativecommons.org/licenses/by/4.0/ 